\title{
Trans Sodium Crocetinate (TSC) to Improve Oxygenation in COVID-19
}

Authors

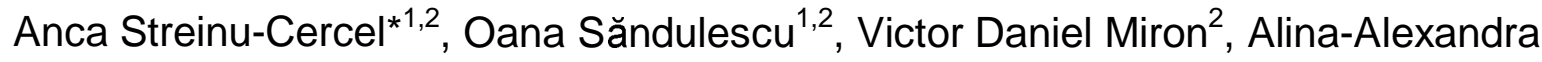

Oană ${ }^{1,2}$, Maria Magdalena Mo $\square$ oi $^{1}$, Christopher D. Galloway ${ }^{3}$, Adrian Streinu-Cercel ${ }^{1,2}$ Institutions:

${ }^{1}$ National Institute for Infectious Diseases "Prof. Dr. Matei Bal $\square$ ”, Bucharest, Romania;

${ }^{2}$ Carol Davila University of Medicine and Pharmacy, Bucharest, Romania

${ }^{3}$ Diffusion Pharmaceuticals, Charlottesville, VA

${ }^{\star}$ Corresponding author

Anca Streinu-Cercel M.D.PhD

National Institute of Infectious Diseases "Prof. Dr. Matei Bals"

Dr. C Grozovici \#1, 021105 Bucharest, Romania

anca.streinucercel@gmail.com

Background: Trans Sodium Crocetinate (TSC) is a bipolar synthetic carotenoid under development as a drug to enhance oxygenation to hypoxic tissue in addition to standard of care. TSC acts via a novel mechanism of action, improving the diffusivity of oxygen in blood plasma. Thus, it is based on physical-chemical principles, unlike most drugs which are based on biochemistry-based mechanisms. We explored the use of escalating doses and multiple daily dosing of TSC as a potential therapeutic for patients 
suffering from hypoxemia due to SARS-CoV-2 infection.

Methods: Individuals $\geq 18$ years who were hospitalized with confirmed SARS-CoV-2 infection and hypoxemia, defined as $\mathrm{SpO}_{2}<94 \%$ on room air or requiring supplemental oxygen, WHO ordinal scale 3 through 7 (exclusive of Extra Corporeal Membrane Oxygenation [ECMO]) were enrolled in cohorts of six subjects, each of whom received the same dose $(0.25,0.5,1.0$, or $1.5 \mathrm{mg} / \mathrm{kg})$ of TSC via intravenous bolus every 6 hours in addition to standard of care (SOC).

This report describes the safety and efficacy results from the lead-in phase of the study and the population pharmacokinetics (PK) analyses. Safety was assessed as the number of serious adverse events and dose-limiting toxicities (DLTs) observed with each dose. Several efficacy parameters were examined in the lead-in phase and descriptive statistics of efficacy parameters are provided. No formal statistical analyses were performed. The population PK analyses were based on previous analyses and examination of the concentration profiles, and two-compartment linear pharmacokinetic models were evaluated and validated. Covariates, including body size, age, sex, organ function, and dose level, were evaluated for inclusion into the model.

Results: TSC was well tolerated. There were no treatment emergent adverse events (TEAEs) reported. There were 2 serious adverse events (SAEs) reported during the study, neither were considered treatment-related. A total of $24(96 \%)$ subjects survived. One subject (4.0\%) died during the study as a result of an SAE (respiratory failure), and that event was determined to be due to COVID-19 complications and not related to study drug.

There was an observed reduction in the time to improvement in WHO Ordinal Scale 
with increasing dose. The median time to 1-point reduction in subjects receiving $0.25 \mathrm{mg} / \mathrm{kg}$ was 11.5 days versus 7.5 days in the $1.5 \mathrm{mg} / \mathrm{kg}$ treatment cohort. The overall range across all doses was 1 day to 28 days. A total of $36.0 \%$ of subjects had a 1-point improvement in WHO Ordinal Scale to Day 7. The $1.5 \mathrm{mg} / \mathrm{kg}$ dose resulted in observed superior outcomes for multiple secondary clinical outcomes: time to 1-point WHO Ordinal Score improvement through Day 29/discharge, 1-point improvement by Day 7 , days to return to room air, and hospital length of stay.

The PK results showed that the two-compartment model fit the data well. Clearance decreased with increasing dose level and there was no evidence that clearance was affected by covariates other than dose level.

Conclusions: These findings suggest that TSC administration every 6 hours at doses up to $1.5 \mathrm{mg} / \mathrm{kg}$ for up to 15 days is safe and well tolerated with predictable pharmacokinetics and demonstrated an observed clinical benefit in the treatment of COVID-19-related hypoxemia.

(ClinicalTrials.gov number, NCT04573322) 


\section{INTRODUCTION}

The novel coronavirus, designated as SARS-CoV-2, and the disease caused by this virus, COVID-19, is still prevalent in many areas of the world, despite widespread vaccination. Globally, as of 17 September 2021, there have been 226,844,344 confirmed cases of COVID-19, including 4,666,334 deaths, reported to WHO. ${ }^{1}$ Current acute treatment options continue to evolve and and may include the use of remdesivir, an antiviral, anti-inflammatory medications; as well well as monoclonal antibody infusions. These have shown some efficacy particularly when administered early in the infection and can all be part of multi-modal therapy for affected patients. Remdesivir has known safety issues in patients with renal dysfunction due to its formulation with sulfobutylether beta-cyclodextrin sodium ${ }^{2}$.

Patients suffering from moderate to severe COVID-19, with pneumonia, could rapidly progress to acute respiratory distress syndrome (ARDS). ${ }^{3,4}$ These patients can often require hospitalization for oxygen supplementation as well as admission to an intensive care unit where mechanical ventilatory (MV) support and possibly extra-corporeal membrane oxygenation (ECMO) or even lung transplant may be needed. COVID-19 leading to severe ARDS is associated with a high degree of morbidity and mortality. Prior to developing ARDS, patients with COVID-19 may experience a period of socalled silent hypoxemia, consisting of observable hypoxemia by oxygen saturation $\left(\mathrm{SpO}_{2}\right)$ measurements, but showing minimal outward signs of respiratory distress. ${ }^{5}$ Impairment of cellular oxygenation is a key factor in the pathophysiology of COVID-19. Endothelial damage can contribute to ventilation-perfusion mismatch leading to hypoxemia, ${ }^{6}$ and in turn severe hypoxemia may lead to multiple organ failure and 
medRxiv preprint doi: https://doi.org/10.1101/2021.10.08.21264719; this version posted October 12, 2021. The copyright holder for this preprint (which was not certified by peer review) is the author/funder, who has granted medRxiv a license to display the preprint in perpetuity. It is made available under a CC-BY-NC-ND 4.0 International license.

death. $^{7}$

Trans sodium crocetinate (TSC) is a novel drug developed to enhance oxygenation to hypoxic tissue. This study evaluated the safety, pharmacokinetics, and efficacy of TSC to improve oxygenation and clinical outcomes in hospitalized hypoxemic patients infected with SARS-CoV-2. 


\section{METHODS}

\section{Trial Design}

The study was designed to have two phases: an open-label lead-in phase and a randomized placebo-controlled phase. The results described herein are from the lead-in phase of the study. This was an open-label, pharmacokinetic, pharmacodynamic, multiple daily, ascending dose, safety and tolerability study in SARS-CoV-2 infected patients with hypoxemia requiring hospitalization (ClinicalTrials.gov number, NCT04573322). The trial was conducted at a single study center in Romania, at The National Institute for Infectious Disease.

The lead-in study enrolled 25 subjects. Eligible subjects received an IV bolus of TSC four times daily (every six hours) for up to 15 days (minimum of 5 days). This study utilized an ascending dose scheme (6 patients per dose cohort), starting with a dose of $0.25 \mathrm{mg} / \mathrm{kg}$.

The protocol is available upon request.

\section{Ethics Statement}

The study was conducted in accordance with the general ethical principles as enunciated in the Declaration of Helsinki (1996) and in conformance with International Conference on Harmonisation (ICH) Good Clinical Practice (GCP) guidance and applicable Health Authority and local requirements regarding Institutional Review Boards, Independent Ethics Committees, informed consent, and other statutes or regulations related to the rights and welfare of human subjects participating in biomedical research. 


\section{Study Participants}

The study population consisted of hospitalized adult ( $\geq 18$ years of age) patients with confirmed SARS-CoV-2 infection and hypoxemia, defined as $\mathrm{SpO}_{2}<94 \%$ on room air or requiring supplemental oxygen, WHO ordinal scale 3-7. Full inclusion and exclusion criteria are provided in the Appendix A.

\section{Intervention and Assessments}

Beginning on Study Day 1, eligible subjects received an IV bolus of TSC four times daily (every six hours) for up to 15 days (minimum of 5 days). Each TSC dose was administered via IV bolus to 6 subjects per dose level $(0.25,0.5,1$, or $1.5 \mathrm{mg} / \mathrm{kg})$. One subject from the $1.0 \mathrm{mg} / \mathrm{kg}$ dose group received one dose of TSC and withdrew therefore an additional patient was enrolled in this cohort. This study utilized a $3+3$ design with an ascending dose scheme. The first group of 3 subjects received TSC at $0.25 \mathrm{mg} / \mathrm{kg}$. If no dose limiting toxicities (DLT) had occurred, an additional 3 subjects were to receive $0.25 \mathrm{mg} / \mathrm{kg} \mathrm{TSC}$. If there were $<33 \%$ observed toxicities among 6 subjects, then another 3 subjects were to receive the next dose level up $(0.5 \mathrm{mg} / \mathrm{kg})$ and so forth. An Independent Safety Monitoring Committee (SMC) was established to review the safety data of a given cohort and approved or disapproved enrollment of the next cohort. At the completion of the lead-in portion of the study, the SMC examined resultant safety data and blood oxygenation data for all subjects and determined all doses were safe and well tolerated with observation of improved clinical outcomes at the highest doses tested.

Key assessments included weekly SARS-CoV-2 reverse transcription polymerase chain reaction (RT-PCR) analysis, WHO 9-point Ordinal Scale assessment (daily, first 
assessment of the day), Glasgow Coma Score (GCS; daily), Sequential Organ Failure Assessment (SOFA; daily), and blood oxygenation was measured via recorded continuous pulse oximetry and the S:F ratio was calculated. Measures of clinical support were assessed and recorded during hospitalization: oxygen requirement, prone positioning, use of remdesivir or other antivirals, use of corticosteroids, non-invasive mechanical ventilation (via mask), mechanical ventilator requirement (via endotracheal tube or tracheostomy), and Extra Corporeal Membrane Oxygenation (ECMO) requirement.

The pharmacokinetics of TSC in blood were analyzed. A dataset suitable for a population pharmacokinetic analysis was assembled. The analyses were conducted with NONMEM software. Based on previous analyses and examination of the concentration profiles, the data were fit to a two-compartment linear pharmacokinetic model. Covariates, including body size, age, sex, organ function, and dose level, were evaluated for inclusion into the model. Model validation included a visual predictive check, a bootstrap analysis, and likelihood profiles for two parameters.

\section{Endpoints}

This report describes the results of the lead-in period which was designed to assess safety and PK. Several efficacy parameters were examined in the lead-in phase, but no statistical analyses were performed. Descriptive statistics of efficacy parameters are provided.

The primary efficacy endpoint was the time to recovery through Day 28 , defined as time to achieve (and maintain through Day 28 ) a WHO ordinal COVID-19 severity scale score of 1, 2 or 3 with a minimum 1-point improvement from baseline. 
The secondary efficacy endpoints included changes in WHO ordinal severity scale, oxygenation parameters (including oxygen saturation to fraction of inspired oxygen ratio $\left(\mathrm{SpO}_{2} / \mathrm{FiO}_{2}\right)$, ventilator-free days, and the time to return to room air), and length of hospitalization.

Safety endpoints included the incidence and severity of adverse events.

The appropriate pharmacokinetic model was selected based on several criteria: graphics displaying ratios of observed-to-population predicted values vs. time and observed vs. population predicted values were examined. A two-compartment linear model was evaluated initially. This was followed by evaluating whether body size should be incorporated into the model, then, the role of other covariates was evaluated.

\section{Statistical Analysis}

No formal statistical analyses were performed. Descriptive statistics were provided for efficacy and safety endpoints. 


\section{RESULTS}

\section{Demographics and Baseline Characteristics}

Thirty-one subjects were screened, and 25 subjects were enrolled in this study. The median age across all dose groups was 55 years and the majority of subjects $(76 \%)$ were less than 65 years old. A total of $52 \%$ were female and all subjects were White. All subjects tested positive for SARS-CoV-2 infection.

Demographics and baseline characteristics for all subjects are presented in Table S 1.

\section{Efficacy}

Time to recovery through Day 28

There was an observed reduction in the time to improvement in WHO Ordinal Scale with increasing dose. The median time to 1-point reduction in subjects receiving $0.25 \mathrm{mg} / \mathrm{kg}$ was 11.5 days versus 7.5 days in the $1.5 \mathrm{mg} / \mathrm{kg}$ treatment cohort. The overall range was 1 day to 28 days (Table $S 2$, Figure $S 1$ ).

A total of $9(36 \%)$ subjects had a 1-point improvement in WHO Ordinal Scale to Day 7. One subject (4\%) had a 1-point decline. No changes were seen in $48 \%$ of subjects (Table S 3).

$\mathrm{SpO}_{2} / \mathrm{FiO}_{2}$ is a marker for peripheral blood saturation of oxygen to fraction of inspired oxygen ratio and was measured for all patients prior to and at several timepoints after each dose was administered. The 1.0 and $1.5 \mathrm{mg} / \mathrm{kg}$ dose groups showed improvement in median pre-dose S/F ratio at Day 5 and later, not seen for $0.25 \mathrm{mg} / \mathrm{kg}$ and $0.50 \mathrm{mg} / \mathrm{kg}$.

The median time required for a subject to return to room air was 7.5 days, ranging from 
0.5 to 52 days. There appeared to be an effect with dose on this parameter, the median number of days for the $1.5 \mathrm{mg} / \mathrm{kg}$ group was 6.5 with a range of 0.5 to 6.5 days (Table $\mathrm{S}$ 4).

The length of hospitalization was assessed and the median length of stay across all dose groups was 8 days and overall range was between 2 to 14 days.

Overall, the $1.5 \mathrm{mg} / \mathrm{kg}$ dose resulted in observed superior outcomes for multiple secondary clinical outcomes: time to 1-point WHO Ordinal Score improvement through Day 29/discharge, 1-point improvement by Day 7, days to return to room air, and hospital length of stay, with only one death (96\% survival observed).

Baseline (pre-dose) $\mathrm{SpO}_{2}$ ranged from 90.0 to 99.0 Day 1 and ranged from 92.0 to 100.0 on Day 10. Baseline $\mathrm{FiO}_{2}$ ranged from 0.28 to 0.75 Day 1 and ranged from 0.21 to 0.75 on Day 10. The median baseline ratio of $\mathrm{SpO}_{2} / \mathrm{FiO}_{2}$ was 217.80 on Day 1 and was 324.25 on Day 10. The change in median $\mathrm{SpO}_{2} / \mathrm{FiO}_{2}$ over time is presented in Table S 8 and graphically in Figure S 3, showing the improvement over time which was most notable at the highest doses of TSC studied.

\section{Safety}

TSC was well tolerated. There were no TEAEs considered related to TSC. There were 2 subjects reporting SAEs, 1 death, and 1 TEAE leading to study drug discontinuation (Table S 5). No DLTs were reported at any dose level tested. A total of 14 (56\%) subjects reported TEAEs. Of these, 5 (20\%) subjects reported Grade 3 or 4 TEAEs. TEAEs from the SOC of Respiratory, Thoracic and Mediastinal Disorders (9 [36.0\%] subjects) and Infections and Infestations (8 [32\%]) were reported most frequently. 
Gastrointestinal disorders and Metabolism and Nutrition disorders were reported in 7 (28.0\%) subjects, each. Most TEAEs were reported in 1 subject each. There were no clinically significant changes in laboratory assessments, vital signs, physical findings, or ECG parameters.

\section{Pharmacokinetics}

Twenty-four subjects with 144 measurable timepoints were included in the PK analyses. One of the subjects was excluded from the analyses due to a PK profile that was inconsistent with a PK profile following an IV bolus dose. In addition, there were 11 trough samples with results that were much higher than expected, and likely taken after IV bolus rather than prior to the dose. These outliers were removed from the mean plasma concentration and the PK analysis. All pre-dose samples of the first dose were below the limit of quantitation $(10 \mathrm{ng} / \mathrm{mL})$ and were set to zero in the PK analysis.

The pharmacokinetics of TSC appear to be nonlinear saturable after IV doses of 0.25 to $1.5 \mathrm{mg} / \mathrm{kg}$ in patients with SARS-COV-2 infection (Figure S 2). Mean CL decreased from $5.38 \mathrm{~mL} / \mathrm{min} / \mathrm{kg}$ at $0.25 \mathrm{mg} / \mathrm{kg}$ to $1.62 \mathrm{~mL} / \mathrm{min} / \mathrm{kg}$ at $1.5 \mathrm{mg} / \mathrm{kg}$. The mean half-life of TSC increased from 0.53 hours to 1.07 hours as dose increased from $0.25 \mathrm{mg} / \mathrm{kg}$ to $1.5 \mathrm{mg} / \mathrm{kg}$. There was no significant accumulation of TSC after multiple IV administration of TSC every 6 hours (Table S 7).

Population pharmacokinetic analyses showed the two-compartment model fit the data well. Although graphics suggested that central compartment volume decreased with weight, models that incorporated an effect of weight or lean body mass on central compartment led to a consistent bias in the relationship between clearance and weight. Therefore, a model with no adjustment for body size was adopted. Increasing dose was 
associated with a decrease in clearance, distribution clearance, and volume of the peripheral compartment. There was no evidence that clearance was affected by concomitant medications, hepatic or renal laboratory variances, or other covariates beyond dose level.

\section{DISCUSSION}

COVID-19 is a respiratory disease caused by a novel coronavirus (SARS-CoV-2) associated with substantial morbidity and mortality. This Phase 1/2 study was conducted in subjects infected with SARS-CoV-2 and was designed to evaluate the safety, pharmacokinetics, and efficacy of a novel agent, TSC, to enhance oxygenation in hospitalized, hypoxemic SARS-CoV-2 infected patients as an adjunct to standard of care.

The diffusion of oxygen through the plasma is considered a rate-limiting step in getting oxygen into the tissues. ${ }^{8}$ Fick's Law predicts that if anatomical relationships remain constant, the change in the concentration (flux) of a substance is directly proportional to both the concentration gradient and the diffusivity. Diffusivity is the ease with which a compound moves due to Brownian motion through a medium. The uptake of oxygen by tissues declines with hypoxemia since the driving concentration gradient from the bloodstream to the tissues is reduced. This results in less oxygen delivered per unit time. Therapies that provide supplemental oxygen to patients provide increased tissue oxygen levels in accordance with Fick's Law by increasing the concentration difference of oxygen between blood and tissue. Modifying the diffusivity of oxygen to improve endorgan delivery and to improve clinical outcomes has not been explored previously in COVID-19 since there has not been a drug available to directly modify diffusivity. Based 
on nonclinical and in vitro evidence, it is suggested that the primary mechanism by which TSC produces physiological effects is by transiently increasing hydrogen bonds between water molecules within the plasma component of blood. By enhancing this organizational matrix within plasma, wider and more direct pathways are created that allow oxygen to passively diffuse from high concentration areas to low concentration areas encountering less resistance. ${ }^{9,10}$ This increased diffusivity, or transfer efficiency, of oxygen to tissues in patients with hypoxemia may improve clinical outcomes.

This report describes the results from the lead-in phase. The lead-in phase was a multiple ascending dose study primarily investigating the safety and pharmacokinetics of TSC with multiple daily dosing not previously studied. Pre-defined clinical efficacy outcomes were also analyzed but no formal statistical analyses were conducted for efficacy; however, descriptive results for efficacy endpoints are presented. The WHO 9-point ordinal scale assessment was the first assessment of the subject's clinical status each day, recording the worst score for the previous day. A reduction in the score derived from this scale is indicative of subject improvement. In the lead-in phase of the study, there was an observed reduction in the amount of time to improvement in WHO Ordinal Scale with increasing dose of TSC, ranging from a median of 11.5 days in the $0.25 \mathrm{mg} / \mathrm{kg}$ dose group to 7 days in the $1.5 \mathrm{mg} / \mathrm{kg}$ dose group. A total of $36 \%$ of subjects had a 1-point improvement in WHO Ordinal Scale to Day 7. The 1.0 and $1.5 \mathrm{mg} / \mathrm{kg}$ dose groups showed improvement in median pre-dose S/F ratio at Day 5 and later, not seen for $0.25 \mathrm{mg} / \mathrm{kg}$ and $0.50 \mathrm{mg} / \mathrm{kg}$. The $1.5 \mathrm{mg} / \mathrm{kg}$ dose resulted in observed superior outcomes for multiple secondary clinical outcomes: time to 1-point WHO Ordinal Score improvement through day 29/discharge, 1-point improvement by day 7 , 
days to return to room air, and hospital length of stay. Another indicator of subject improvement with TSC treatment included an increase in median $\mathrm{SpO}_{2} / \mathrm{FiO}_{2}(\mathrm{~S} / \mathrm{F})$ over time; these results are observational.

No new safety signals were identified as a result of this study. There were no TSC related TEAEs reported. Serious AEs and the death of 1 subject were assessed to be related to the underlying condition of SARS-CoV-2 infection. The results of the PK analyses in this study were consistent with other studies with TSC showing that increasing dose of TSC was associated with a decrease in clearance. There was no evidence that clearance was affected by covariates other than dose level.

These findings suggest that administration of TSC every 6 hours daily at doses up to $1.5 \mathrm{mg} / \mathrm{kg}$ for up to 15 days was well tolerated with a predictable pharmacokinetic profile independent of covariates aside from dose. Additionally, there were observed improvements in multiple clinical endpoints at the higher doses of TSC in the treatment of patients with COVID-19-related hypoxia.

\section{DATA SHARING}

A data sharing statement provided by the authors is available with the full text of this article.

\section{SUPPORTED BY}

Supported by Diffusion Pharmaceuticals, Inc.

\section{FINANCIAL DISCLOSURE}

Disclosure forms provided by the authors are available with the full text of this article. 
medRxiv preprint doi: https://doi.org/10.1101/2021.10.08.21264719; this version posted October 12, 2021. The copyright holder for this preprint (which was not certified by peer review) is the author/funder, who has granted medRxiv a license to display the preprint in perpetuity. It is made available under a CC-BY-NC-ND 4.0 International license.

\section{ACKNOWLEDGEMENT}

We thank the study participants; their families; the investigational site members involved in this trial; the Trial Team; the members of the Data and Safety Monitoring Board; and our CRO partners. 


\section{REFERENCES}

1. WHO Coronavirus (COVID-19) Dashboard. https://covid19.who.int/ (Accessed 18 September 2021)

2. NIH COVID-19 Treatment Guidelines https://www.covid19treatmentguidelines.nih.gov/therapies/antiviraltherapy/remdesivir/ accessed 02 October 2021.

3. Tsatsakis A, Calina D, Falzone L, Petrakis D, Mitrut R, Siokas V, et al. SARSCoV-2 pathophysiology and its clinical implications: An integrative overview of the pharmacotherapeutic management of COVID-19. Food and Chemical Toxicology 2020; 146: 111769.

4. Maveddat A, Mallah H, Rao S, Ali K, Sherali S, Nugent K. Severe Acute Respiratory Distress Syndrome Secondary to Coronavirus 2 (SARS-CoV-2). Int J Occup Environ Med. 2020; 11(4):157-178. doi: 10.34172/ijoem.2020.2202. PMID: 33098401; PMCID: PMC7740045.

5. Teo J. Early Detection of Silent Hypoxia in Covid-19 Pneumonia Using Smartphone Pulse Oximetry. J Med Syst. 2020;44(8):134. Published 2020 Jun 19. doi:10.1007/s10916-020-01587-6

6. Marini JJ, Gattinoni L. Management of COVID-19 Respiratory Distress. JAMA. 2020; 323(22):2329-2330. doi: 10.1001/jama.2020.6825. PMID: 32329799.

7. Sharma A, Tiwari S, Deb M K, Marty JL. Severe acute respiratory syndrome coronavirus-2 (SARS-CoV-2): a global pandemic and treatment strategies. International Journal of Antimicrobial Agents 2020; 56: 106054.

8. Huxley $\mathrm{VH}$, Kutchai $\mathrm{H}$. The effect of the red cell membrane and a diffusion boundary layer on the rate of oxygen uptake by human erythrocytes. J Physiol. $1981 ; 316: 75-83$.

9. Stennett AK, Murray RJ, Roy JW, Gainer JL. Trans-sodium crocetinate and hemorrhagic shock. Shock. 2007; 28339-344.

10. Gainer JL, Stennett AK, Murray RJ. The effect of trans sodium crocetinate (TSC) in a rat oleic acid model of acute lunch injury. Pulm. Pharmacol. Ther. 2005; 18:213-216. 


\section{Supplemental Tables}

Table S 1 Subject Demographics

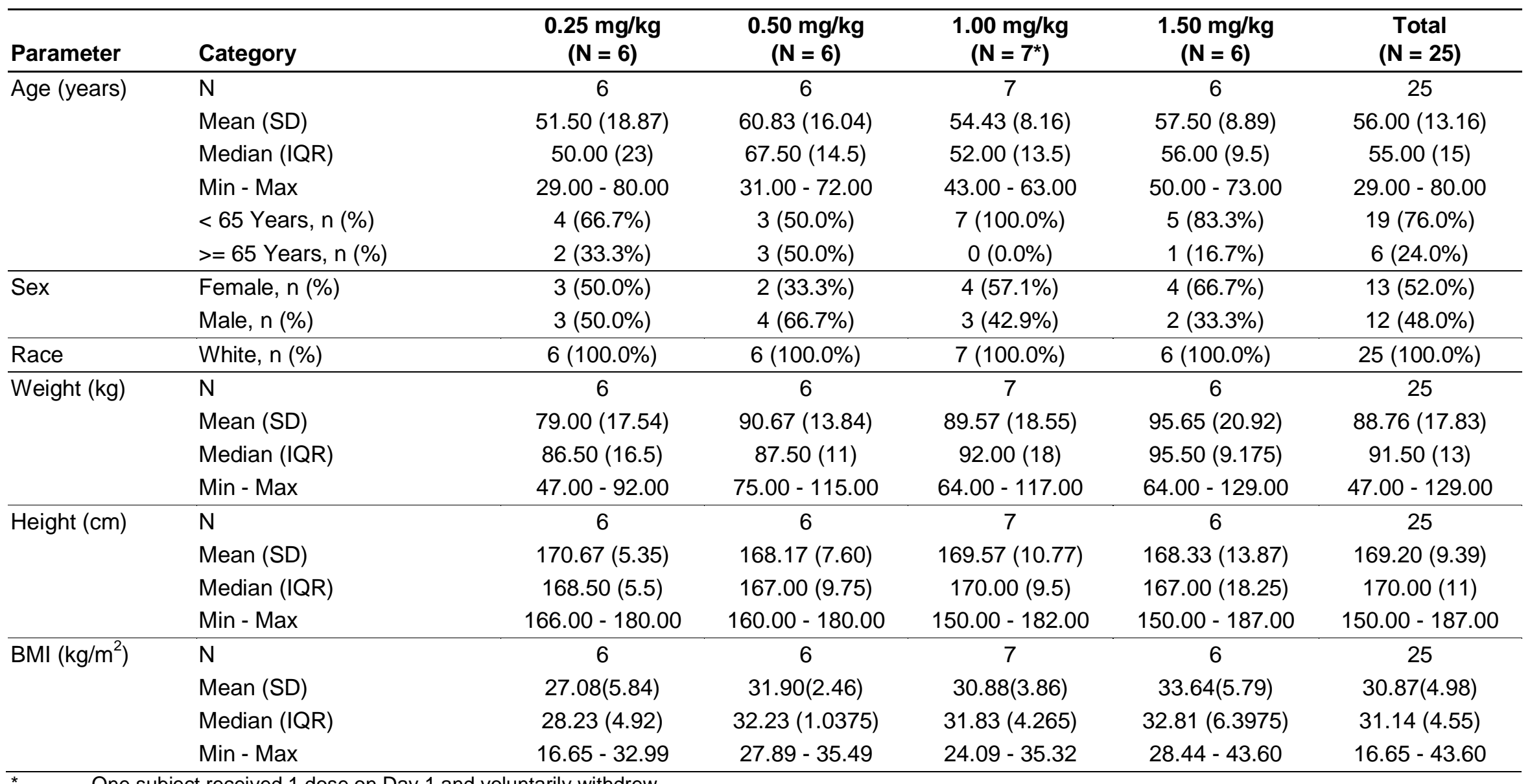

One subject received 1 dose on Day 1 and voluntarily withdrew

Source: Diffusion Pharmaceuticals, Inc. Clinical Study Report: 100-303, Table 14.1.2.1

Percentages are based on the Safety Population. 
Table S 2 Summary of Time* (Days) to 1-Point Improvement in WHO Ordinal Severity Scale Through Day 29/Discharge

\begin{tabular}{|c|c|c|c|c|c|}
\hline Statistics & $\begin{array}{c}0.25 \mathrm{mg} / \mathrm{kg} \\
(\mathrm{N}=6)\end{array}$ & $\begin{array}{c}0.50 \mathrm{mg} / \mathrm{kg} \\
(\mathrm{N}=6)\end{array}$ & $\begin{array}{c}1.00 \mathrm{mg} / \mathrm{kg} \\
(\mathrm{N}=7)\end{array}$ & $\begin{array}{c}1.50 \mathrm{mg} / \mathrm{kg} \\
(\mathrm{N}=6)\end{array}$ & $\begin{array}{c}\text { Total } \\
(N=25)\end{array}$ \\
\hline $\mathrm{N}$ & 6 & 6 & 7 & 6 & 25 \\
\hline Mean (SD) & 14.33 (11.54) & $13.67(8.43)$ & $7.71(4.31)$ & $7.50(1.22)$ & 10.68 (7.63) \\
\hline Median & 11.50 & 10.50 & 8.00 & 7.00 & 7.00 \\
\hline Min - Max & $3.00-28.00$ & $7.00-28.00$ & $1.00-14.00$ & $7.00-10.00$ & $1.00-28.00$ \\
\hline
\end{tabular}

Source: Table 14.2.1.1

*: Subjects who had no 1-point improvement in WHO ordinal severity scale during the study, the time (day) to 1-point improvement was imputed by last study day (Day 29/Discharge).

\section{Figure S 1 Change in Median Number of Days to 1-Point Improvement in WHO Ordinal Severity Scale}

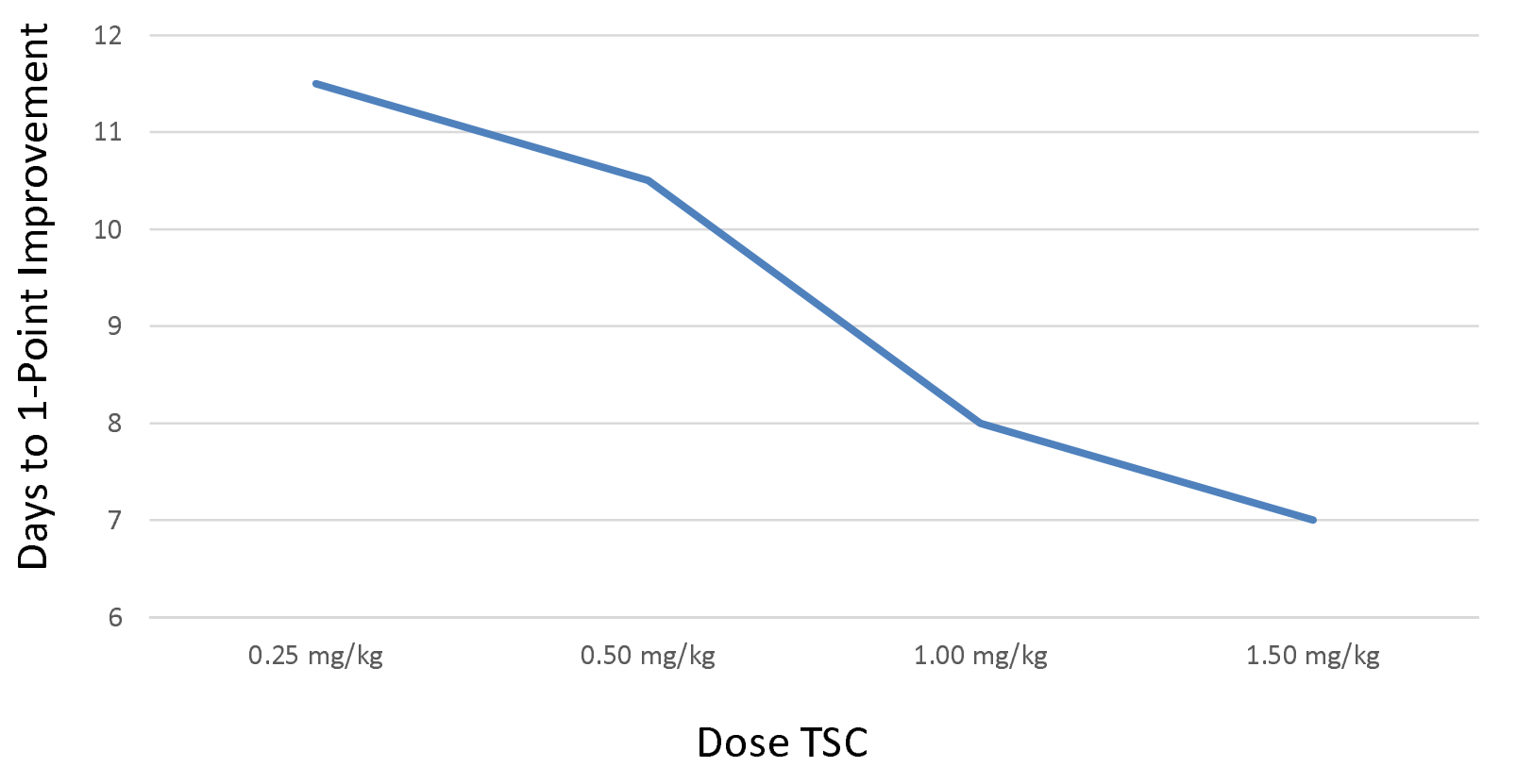


Table S 3 Number and Percentage of Patients by WHO Ordinal Severity Scale Change from Baseline to Day 7

\begin{tabular}{|c|c|c|c|c|c|}
\hline Category Change & $\begin{array}{c}0.25 \mathrm{mg} / \mathrm{kg} \\
(\mathrm{N}=6)\end{array}$ & $\begin{array}{c}0.50 \mathrm{mg} / \mathrm{kg} \\
(\mathrm{N}=6)\end{array}$ & $\begin{array}{c}1.00 \mathrm{mg} / \mathrm{kg} \\
(\mathrm{N}=7)\end{array}$ & $\begin{array}{c}1.50 \mathrm{mg} / \mathrm{kg} \\
(\mathrm{N}=6)\end{array}$ & $\begin{array}{c}\text { Total } \\
(\mathrm{N}=25)\end{array}$ \\
\hline 1 Point Worse from Day 1 to Day 7 & $0(0.0 \%)$ & $1(16.7 \%)$ & $0(0.0 \%)$ & $0(0.0 \%)$ & $1(4.0 \%)$ \\
\hline 1 Point Improvement from Day 1 to Day 7 & $1(16.7 \%)$ & $2(33.3 \%)$ & $1(14.3 \%)$ & $5(83.3 \%)$ & $9(36.0 \%)$ \\
\hline No Data Collected on Day 7 & $2(33.3 \%)$ & $0(0.0 \%)$ & $1(14.3 \%)$ & $0(0.0 \%)$ & $3(12.0 \%)$ \\
\hline
\end{tabular}

Source: Table 14.2.1.2 
Table S 4 Summary of Time* (Days) to Return to Room Air by Treatment Group

\begin{tabular}{|c|c|c|c|c|c|}
\hline Statistics & $\begin{array}{c}0.25 \mathrm{mg} / \mathrm{kg} \\
(\mathrm{N}=6)\end{array}$ & $\begin{array}{c}0.50 \mathrm{mg} / \mathrm{kg} \\
(\mathrm{N}=6)\end{array}$ & $\begin{array}{c}1.00 \mathrm{mg} / \mathrm{kg} \\
(\mathrm{N}=7)\end{array}$ & $\begin{array}{c}1.50 \mathrm{mg} / \mathrm{kg} \\
(\mathrm{N}=6)\end{array}$ & $\begin{array}{c}\text { Total } \\
(\mathrm{N}=25)\end{array}$ \\
\hline $\mathrm{N}$ & 6 & 6 & 7 & 6 & 25 \\
\hline Median & 6.75 & 10.75 & 8.50 & 6.50 & 7.50 \\
\hline Min - Max & $1.50-17.50$ & $6.00-52.00$ & $7.50-28.00$ & $0.50-6.50$ & $0.50-52.00$ \\
\hline
\end{tabular}

Source: Table 14.2.2.1

*: For multiple times of using supplemental oxygen, the last end date was used to count the time (day) to return room air. 
Table S 5 Overall Summary of Subjects with TEAE during Lead-In Phase Safety Population

\begin{tabular}{|c|c|c|c|c|c|}
\hline & $\begin{array}{c}0.25 \mathrm{mg} / \mathrm{kg} \\
(\mathrm{N}=6)\end{array}$ & $\begin{array}{c}0.50 \mathrm{mg} / \mathrm{kg} \\
(\mathrm{N}=6)\end{array}$ & $\begin{array}{c}1.00 \mathrm{mg} / \mathrm{kg} \\
(\mathrm{N}=7)\end{array}$ & $\begin{array}{c}1.50 \mathrm{mg} / \mathrm{kg} \\
(\mathrm{N}=6)\end{array}$ & $\begin{array}{c}\text { Total } \\
(\mathrm{N}=25)\end{array}$ \\
\hline Patients with any Serious TEAE & $1(16.7 \%)$ & $1(16.7 \%)$ & $0(0.0 \%)$ & $0(0.0 \%)$ & $2(8.0 \%)$ \\
\hline Patients with any TEAE resulting in death & $1(16.7 \%)$ & $0(0.0 \%)$ & $0(0.0 \%)$ & $0(0.0 \%)$ & $1(4.0 \%)$ \\
\hline Patients with any TEAE leading to study drug discontinuation & $0(0.0 \%)$ & $1(16.7 \%)$ & $0(0.0 \%)$ & $0(0.0 \%)$ & $1(4.0 \%)$ \\
\hline Patients with any TEAE leading to study drug interruption & $0(0.0 \%)$ & $0(0.0 \%)$ & $0(0.0 \%)$ & $0(0.0 \%)$ & $0(0.0 \%)$ \\
\hline
\end{tabular}

Source: Table 14.3.1.1

$\%$ is based on the total numbers of Safety Population,

TEAE = Treatment-Emergent Adverse Events, TDL = Dose Limiting Toxicity 
Table S 6 TEAEs Reported in $\geq 2$ Subjects per SOC During the Lead-in Phase Safety Population

\begin{tabular}{|c|c|c|c|c|c|}
\hline $\begin{array}{l}\text { System Organ Class } \\
\text { Preferred Term }\end{array}$ & $\begin{array}{c}0.25 \\
\mathrm{mg} / \mathrm{kg} \\
(\mathrm{N}=6)\end{array}$ & $\begin{array}{c}0.50 \\
\mathrm{mg} / \mathrm{kg} \\
(\mathrm{N}=6)\end{array}$ & $\begin{array}{c}1.00 \\
\mathrm{mg} / \mathrm{kg} \\
(\mathrm{N}=7)\end{array}$ & $\begin{array}{c}1.50 \\
\mathrm{mg} / \mathrm{kg} \\
(\mathrm{N}=6)\end{array}$ & $\begin{array}{c}\text { Total } \\
(\mathrm{N}=25)\end{array}$ \\
\hline $\begin{array}{l}\text { Number of Patients with Any } \\
\text { TEAE }\end{array}$ & $3(50.0 \%)$ & $4(66.7 \%)$ & 5 (71.4\%) & 2 (33.3\%) & $\begin{array}{c}14 \\
(56.0 \%)\end{array}$ \\
\hline Cardiac Disorders & $1(16.7 \%)$ & $0(0.0 \%)$ & $1(14.3 \%)$ & $0(0.0 \%)$ & $2(8.0 \%)$ \\
\hline Bradycardia & $0(0.0 \%)$ & $0(0.0 \%)$ & $1(14.3 \%)$ & $0(0.0 \%)$ & $1(4.0 \%)$ \\
\hline Congestive cardiomyopathy & $1(16.7 \%)$ & $0(0.0 \%)$ & $0(0.0 \%)$ & $0(0.0 \%)$ & $1(4.0 \%)$ \\
\hline Gastrointestinal Disorders & $5(83.3 \%)$ & $2(33.3 \%)$ & $0(0.0 \%)$ & $0(0.0 \%)$ & $7(28.0 \%)$ \\
\hline Diarrhoea & $0(0.0 \%)$ & $1(16.7 \%)$ & $0(0.0 \%)$ & $0(0.0 \%)$ & $1(4.0 \%)$ \\
\hline Dyspepsia & $1(16.7 \%)$ & $0(0.0 \%)$ & $0(0.0 \%)$ & $0(0.0 \%)$ & $1(4.0 \%)$ \\
\hline Hernial eventration & $1(16.7 \%)$ & $0(0.0 \%)$ & $0(0.0 \%)$ & $0(0.0 \%)$ & $1(4.0 \%)$ \\
\hline Hiatus hernia & $1(16.7 \%)$ & $1(16.7 \%)$ & $0(0.0 \%)$ & $0(0.0 \%)$ & $2(8.0 \%)$ \\
\hline Nausea & $1(16.7 \%)$ & $0(0.0 \%)$ & $0(0.0 \%)$ & $0(0.0 \%)$ & $1(4.0 \%)$ \\
\hline Vomiting & $1(16.7 \%)$ & $0(0.0 \%)$ & $0(0.0 \%)$ & $0(0.0 \%)$ & $1(4.0 \%)$ \\
\hline $\begin{array}{l}\text { General Disorders And } \\
\text { Administration Site Conditions }\end{array}$ & $0(0.0 \%)$ & $1(16.7 \%)$ & $1(14.3 \%)$ & $0(0.0 \%)$ & $2(8.0 \%)$ \\
\hline Non-cardiac chest pain & $0(0.0 \%)$ & $0(0.0 \%)$ & $1(14.3 \%)$ & $0(0.0 \%)$ & $1(4.0 \%)$ \\
\hline Oedema peripheral & $0(0.0 \%)$ & $1(16.7 \%)$ & $0(0.0 \%)$ & $0(0.0 \%)$ & $1(4.0 \%)$ \\
\hline Hepatobiliary Disorders & $2(33.3 \%)$ & $0(0.0 \%)$ & $0(0.0 \%)$ & $0(0.0 \%)$ & $2(8.0 \%)$ \\
\hline Hepatic steatosis & $1(16.7 \%)$ & $0(0.0 \%)$ & $0(0.0 \%)$ & $0(0.0 \%)$ & $1(4.0 \%)$ \\
\hline Hepatocellular injury & $1(16.7 \%)$ & $0(0.0 \%)$ & $0(0.0 \%)$ & $0(0.0 \%)$ & $1(4.0 \%)$ \\
\hline Infections And Infestations & $2(33.3 \%)$ & $5(83.3 \%)$ & $1(14.3 \%)$ & $0(0.0 \%)$ & $8(32.0 \%)$ \\
\hline Clostridium difficile colitis & $0(0.0 \%)$ & $0(0.0 \%)$ & $1(14.3 \%)$ & $0(0.0 \%)$ & $1(4.0 \%)$ \\
\hline Oral candidiasis & $0(0.0 \%)$ & $1(16.7 \%)$ & $0(0.0 \%)$ & $0(0.0 \%)$ & $1(4.0 \%)$ \\
\hline Pneumonia bacterial & $1(16.7 \%)$ & $0(0.0 \%)$ & $0(0.0 \%)$ & $0(0.0 \%)$ & $1(4.0 \%)$ \\
\hline $\begin{array}{l}\text { Respiratory tract infection } \\
\text { bacterial }\end{array}$ & $0(0.0 \%)$ & $1(16.7 \%)$ & $0(0.0 \%)$ & $0(0.0 \%)$ & $1(4.0 \%)$ \\
\hline Respiratory tract infection fungal & $0(0.0 \%)$ & $1(16.7 \%)$ & $0(0.0 \%)$ & $0(0.0 \%)$ & $1(4.0 \%)$ \\
\hline Sepsis & $0(0.0 \%)$ & $1(16.7 \%)$ & $0(0.0 \%)$ & $0(0.0 \%)$ & $1(4.0 \%)$ \\
\hline Superinfection bacterial & $0(0.0 \%)$ & $1(16.7 \%)$ & $0(0.0 \%)$ & $0(0.0 \%)$ & $1(4.0 \%)$ \\
\hline Urinary tract infection fungal & $1(16.7 \%)$ & $0(0.0 \%)$ & $0(0.0 \%)$ & $0(0.0 \%)$ & $1(4.0 \%)$ \\
\hline $\begin{array}{l}\text { Injury, Poisoning And Procedural } \\
\text { Complications }\end{array}$ & $0(0.0 \%)$ & $2(33.3 \%)$ & $0(0.0 \%)$ & $0(0.0 \%)$ & $2(8.0 \%)$ \\
\hline Contusion & $0(0.0 \%)$ & $2(33.3 \%)$ & $0(0.0 \%)$ & $0(0.0 \%)$ & $2(8.0 \%)$ \\
\hline Investigations & $1(16.7 \%)$ & $1(16.7 \%)$ & $0(0.0 \%)$ & $0(0.0 \%)$ & $2(8.0 \%)$ \\
\hline \multirow{2}{*}{$\begin{array}{l}\text { Blood creatinine increased } \\
\text { Electrocardiogram QT } \\
\text { prolonged }\end{array}$} & $0(0.0 \%)$ & $1(16.7 \%)$ & $0(0.0 \%)$ & $0(0.0 \%)$ & $1(4.0 \%)$ \\
\hline & $1(16.7 \%)$ & $0(0.0 \%)$ & $0(0.0 \%)$ & $0(0.0 \%)$ & $1(4.0 \%)$ \\
\hline Metabolism And Nutrition Disorders & $0(0.0 \%)$ & $5(83.3 \%)$ & $0(0.0 \%)$ & $2(33.3 \%)$ & $7(28.0 \%)$ \\
\hline Hyperglycaemia & $0(0.0 \%)$ & $0(0.0 \%)$ & $0(0.0 \%)$ & $1(16.7 \%)$ & $1(4.0 \%)$ \\
\hline Hyperkalaemia & $0(0.0 \%)$ & $2(33.3 \%)$ & $0(0.0 \%)$ & $0(0.0 \%)$ & $2(8.0 \%)$ \\
\hline Hypoalbuminaemia & $0(0.0 \%)$ & $1(16.7 \%)$ & $0(0.0 \%)$ & $1(16.7 \%)$ & $2(8.0 \%)$ \\
\hline Hyponatraemia & $0(0.0 \%)$ & $1(16.7 \%)$ & $0(0.0 \%)$ & $0(0.0 \%)$ & $1(4.0 \%)$ \\
\hline Oedema peripheral & $0(0.0 \%)$ & $1(16.7 \%)$ & $0(0.0 \%)$ & $0(0.0 \%)$ & $1(4.0 \%)$ \\
\hline Psychiatric Disorders & $1(16.7 \%)$ & $0(0.0 \%)$ & $0(0.0 \%)$ & $1(16.7 \%)$ & $2(8.0 \%)$ \\
\hline
\end{tabular}


medRxiv preprint doi: https://doi.org/10.1101/2021.10.08.21264719; this version posted October 12, 2021. The copyright holder for this preprint (which was not certified by peer review) is the author/funder, who has granted medRxiv a license to display the preprint in perpetuity. It is made available under a CC-BY-NC-ND 4.0 International license .

\begin{tabular}{|c|c|c|c|c|c|}
\hline $\begin{array}{c}\text { System Organ Class } \\
\text { Preferred Term }\end{array}$ & $\begin{array}{c}0.25 \\
\mathrm{mg} / \mathrm{kg} \\
(\mathrm{N}=6)\end{array}$ & $\begin{array}{c}0.50 \\
\mathrm{mg} / \mathrm{kg} \\
(\mathrm{N}=6)\end{array}$ & $\begin{array}{c}1.00 \\
\mathrm{mg} / \mathrm{kg} \\
(\mathrm{N}=7)\end{array}$ & $\begin{array}{c}1.50 \\
\mathrm{mg} / \mathrm{kg} \\
(\mathrm{N}=6)\end{array}$ & $\begin{array}{c}\text { Total } \\
(\mathrm{N}=25)\end{array}$ \\
\hline Depression & $1(16.7 \%)$ & $0(0.0 \%)$ & $0(0.0 \%)$ & $0(0.0 \%)$ & $1(4.0 \%)$ \\
\hline Insomnia & $0(0.0 \%)$ & $0(0.0 \%)$ & $0(0.0 \%)$ & $1(16.7 \%)$ & $1(4.0 \%)$ \\
\hline Renal And Urinary Disorders & $1(16.7 \%)$ & $0(0.0 \%)$ & $2(28.6 \%)$ & $0(0.0 \%)$ & $3(12.0 \%)$ \\
\hline Dysuria & $0(0.0 \%)$ & $0(0.0 \%)$ & $2(28.6 \%)$ & $0(0.0 \%)$ & $2(8.0 \%)$ \\
\hline Urinary retention & $1(16.7 \%)$ & $0(0.0 \%)$ & $0(0.0 \%)$ & $0(0.0 \%)$ & $1(4.0 \%)$ \\
\hline $\begin{array}{l}\text { Respiratory, Thoracic And } \\
\text { Mediastinal Disorders }\end{array}$ & $\begin{array}{c}6 \\
(100.0 \%)\end{array}$ & $2(33.3 \%)$ & $0(0.0 \%)$ & $1(16.7 \%)$ & $9(36.0 \%)$ \\
\hline Epistaxis & $0(0.0 \%)$ & $1(16.7 \%)$ & $0(0.0 \%)$ & $0(0.0 \%)$ & $1(4.0 \%)$ \\
\hline Interstitial lung disease & $3(50.0 \%)$ & $0(0.0 \%)$ & $0(0.0 \%)$ & $0(0.0 \%)$ & $3(12.0 \%)$ \\
\hline Pleural effusion & $0(0.0 \%)$ & $0(0.0 \%)$ & $0(0.0 \%)$ & $1(16.7 \%)$ & $1(4.0 \%)$ \\
\hline Pulmonary hypertension & $1(16.7 \%)$ & $0(0.0 \%)$ & $0(0.0 \%)$ & $0(0.0 \%)$ & $1(4.0 \%)$ \\
\hline Respiratory failure & $2(33.3 \%)$ & $1(16.7 \%)$ & $0(0.0 \%)$ & $0(0.0 \%)$ & $3(12.0 \%)$ \\
\hline Vascular Disorders & $0(0.0 \%)$ & $0(0.0 \%)$ & $2(28.6 \%)$ & $1(16.7 \%)$ & $3(12.0 \%)$ \\
\hline Hypertension & $0(0.0 \%)$ & $0(0.0 \%)$ & $1(14.3 \%)$ & $0(0.0 \%)$ & $1(4.0 \%)$ \\
\hline Hypotension & $0(0.0 \%)$ & $0(0.0 \%)$ & $1(14.3 \%)$ & $0(0.0 \%)$ & $1(4.0 \%)$ \\
\hline Phlebitis & $0(0.0 \%)$ & $0(0.0 \%)$ & $0(0.0 \%)$ & $1(16.7 \%)$ & $1(4.0 \%)$ \\
\hline
\end{tabular}

Source: Table 14.3.1.2 
Figure S 2 Mean (+SD) TSC Plasma Concentration-Time Profiles by Dose Cohort Following Multiple IV Administration of TSC Every Six Hours, Linear Scale

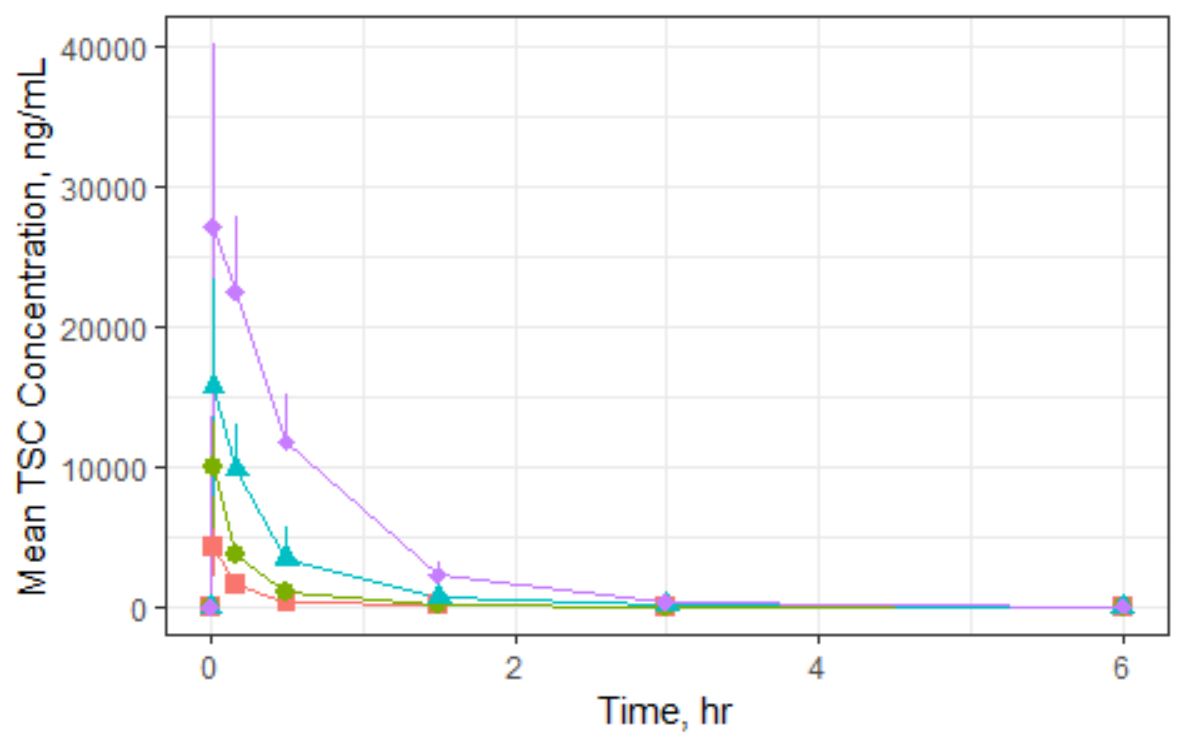

Dose

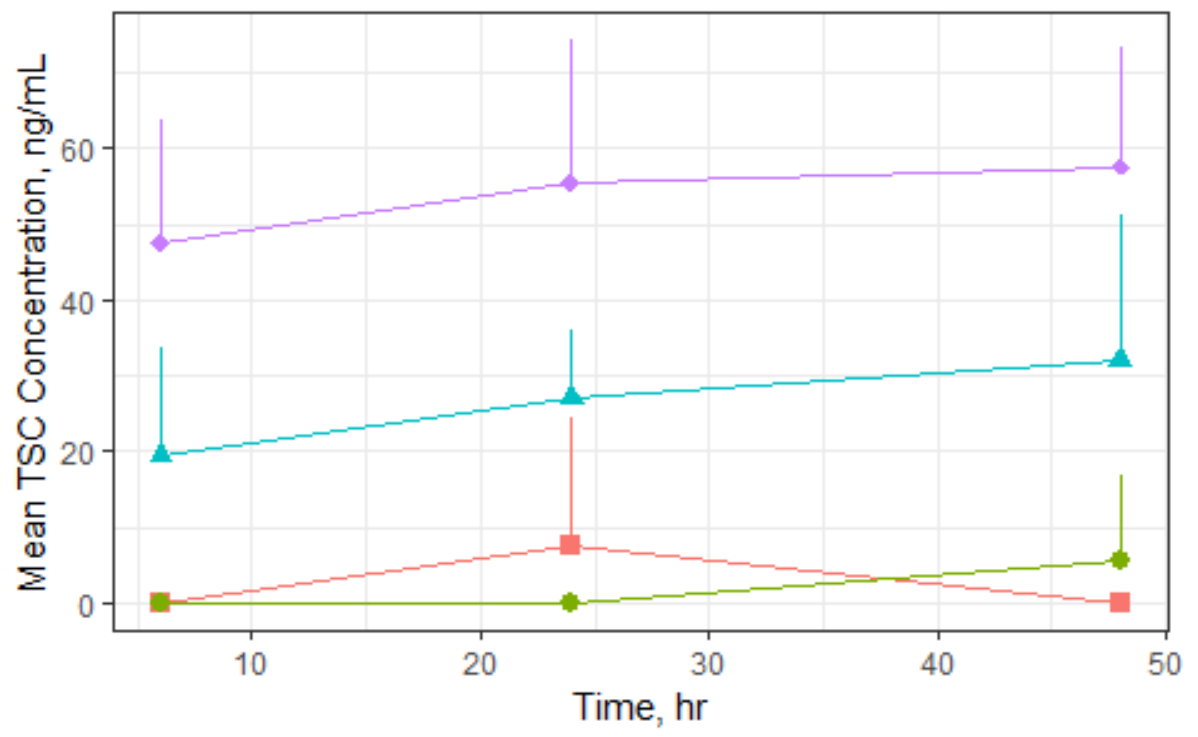

Dose

- $0.25 \mathrm{mg} / \mathrm{kg}$

- $0.5 \mathrm{mg} / \mathrm{kg}$

- $1 \mathrm{mg} / \mathrm{kg}$

$1.5 \mathrm{mg} / \mathrm{kg}$ 
Table S $7 \quad$ Summary of Pharmacokinetic Parameters of TSC Following IV Bolus Administration of TSC by Dose Cohort of Patients with SARS-CoV-2 Infection and Hypoxemia in Study 100-301

\begin{tabular}{|c|c|c|c|c|}
\hline \multirow[b]{2}{*}{ Parameter } & \multicolumn{4}{|c|}{ Dose } \\
\hline & $\begin{array}{c}0.25 \mathrm{mg} / \mathrm{kg} \\
(\mathrm{N}=6)\end{array}$ & $\begin{array}{c}0.5 \mathrm{mg} / \mathrm{kg} \\
(\mathrm{N}=6)\end{array}$ & $\begin{array}{c}1 \mathrm{mg} / \mathrm{kg} \\
(\mathrm{N}=7)\end{array}$ & $\begin{array}{c}1.5 \mathrm{mg} / \mathrm{kg} \\
(\mathrm{N}=6)\end{array}$ \\
\hline $\mathrm{C}_{\max }( \pm \mathrm{SD}) \mathrm{ng} / \mathrm{mL}$ & $4197 \pm 1295$ & $10072 \pm 3188^{*}$ & $17829 \pm 3519$ & $28783 \pm 9765$ \\
\hline$T_{\max } h$ & 0.0167 & $0.0167^{*}$ & 0.0167 & 0.0919 \\
\hline $\mathrm{AUC}_{0-\mathrm{t}}( \pm \mathrm{SD}) \mathrm{h}^{*} \mathrm{ng} / \mathrm{mL}$ & $910 \pm 374$ & $2240 \pm 335^{\star}$ & $6293 \pm 2564$ & $16682 \pm 4831$ \\
\hline $\mathrm{AUC}_{0-\infty}( \pm \mathrm{SD}) \mathrm{h}^{*} \mathrm{ng} / \mathrm{mL}$ & $934 \pm 374$ & $2264 \pm 330^{*}$ & $6332 \pm 2563$ & $16756 \pm 4844$ \\
\hline$t_{1 / 2 z}( \pm S D) h$ & $0.53 \pm 0.156$ & $0.604 \pm 0.0535^{\star}$ & $0.929 \pm 0.317$ & $1.07 \pm 0.118$ \\
\hline $\mathrm{CL}( \pm \mathrm{SD}) \mathrm{mL} / \mathrm{min} / \mathrm{kg}$ & $5.38 \pm 2.96$ & $3.74 \pm 0.525^{\star}$ & $2.97 \pm 1.02$ & $1.62 \pm 0.563$ \\
\hline$V z( \pm S D) L / k g$ & $0.225 \pm 0.0776$ & $0.197 \pm 0.0415^{*}$ & $0.238 \pm 0.111$ & $0.151 \pm 0.0552)$ \\
\hline
\end{tabular}

Source: PK Study Report Protocol number: 100-303

$\mathrm{AUC}_{0-\infty}$, area under the concentration curve from time zero to infinity; $\mathrm{AUC}_{0-\mathrm{t}}$, area under the concentration vs time curve from time zero to tau; $\mathrm{C}_{\max }$, maximum concentration; $\mathrm{CL}$, clearance; $\mathrm{SD}$, standard deviation; $\mathrm{t}_{1 / 2 \mathrm{z}}$, terminal elimination half-life; $\mathrm{T}_{\max }$, time to maximum concentration $\mathrm{Vz}$, volume in terminal state

$*_{n}=5$ Samples from 1 subject were excluded from the analysis because PK profile was not recognized as a PK profile after an IV bolus dose 
medRxiv preprint doi: https://doi.org/10.1101/2021.10.08.21264719; this version posted October 12, 2021. The copyright holder for this preprint (which was not certified by peer review) is the author/funder, who has granted medRxiv a license to display the preprint in perpetuity.

It is made available under a CC-BY-NC-ND 4.0 International license.

\section{Table S 8 Change in Median $\mathrm{SpO}_{2} / \mathrm{FiO}_{2}$ Ratio Over Time}

\begin{tabular}{lccccc} 
& \multicolumn{1}{c}{$\mathbf{0 . 2 5}$} & $\mathbf{0 . 5 0}$ & $\mathbf{1 . 0 0}$ & $\mathbf{1 . 5 0}$ & Total \\
\cline { 2 - 6 } $\mathbf{m g} / \mathbf{k g}$ & $\mathbf{m g} / \mathbf{k g}$ & $\mathbf{m g} / \mathbf{k g}$ & $\mathbf{m g} / \mathbf{k g}$ & \\
\cline { 2 - 6 } Baseline & 284.55 & 127.35 & 176.4 & 245 & 217.8 \\
Day 2 & 302.55 & 128 & 207 & 263.95 & 221.35 \\
Day 3 & 255.85 & 132.3 & 232.5 & 277.55 & 242.5 \\
Day 4 & 294.45 & 130.2 & 289.05 & 330 & 275 \\
Day 5 & 241.95 & 132.25 & 316.55 & 369.15 & 304.7 \\
Day 6 & 301.9 & 239.65 & 326.7 & 461.9 & 330 \\
Day 7 & 219.6 & 132 & 405.35 & 461.9 & 341.8 \\
Day 8 & 219.7 & 142 & 410.15 & 461.9 & 331.5 \\
Day 9 & 291.7 & 158.1 & 471.4 & 457.1 & 452.4 \\
Day 10 & 122.7 & 158.5 & 469.05 & 466.7 & 324.25
\end{tabular}

Figure S 3 Summary of Oxygen Saturation (via Pulse Oximetry) Results by Study Day: Median $\mathrm{SpO}_{2} / \mathrm{FiO}_{2}$ Ratio

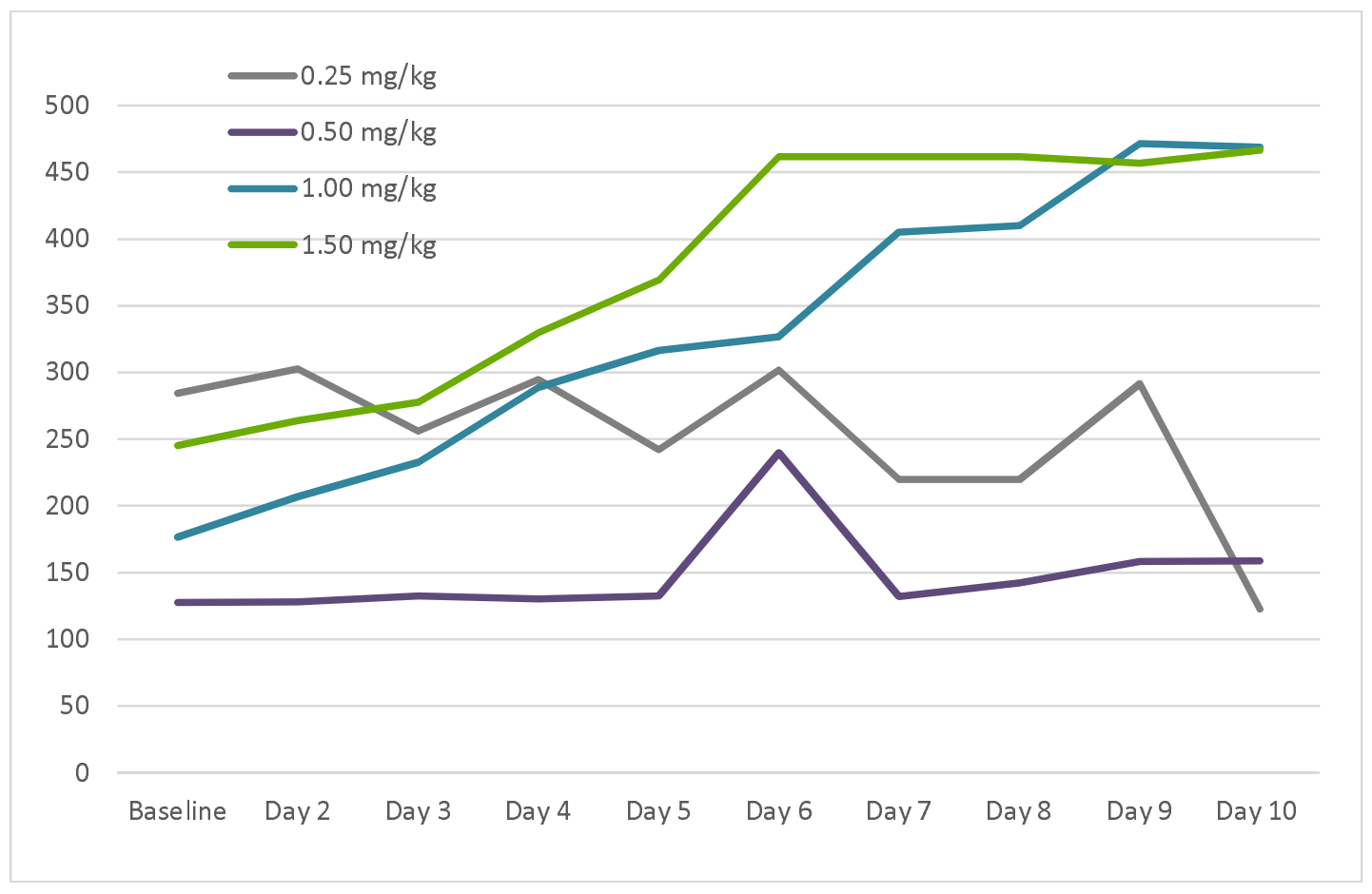




\section{Appendix A Inclusion/Exclusion Criteria Inclusion Criteria}

1. Hospitalized subjects with confirmed SARS-CoV-2 infection and hypoxemia, defined as $\mathrm{SpO} 2<94 \%$ on room air or requiring supplemental oxygen (inclusive of nasal cannula, high flow oxygen, non-invasive ventilation, and mechanical ventilation)

2. Laboratory-confirmed SARS-CoV-2 infection as determined by rtPCR, or other commercial or public health assay in any specimen within 7 days prior to enrollment.

3. WHO ordinal scale score of 3 through 7 (exclusive of ECMO) at baseline

4. Male or non-pregnant female adult $\geq 18$ years of age at time of enrollment.

5. Subject (or legally authorized representative) provides written informed consent prior to initiation of any study procedures.

6. Understands and agrees to comply with planned study procedures.

7. Illness of any duration

8. Women of childbearing potential must have a negative blood pregnancy test at the screening/baseline visit and agree to use two forms of birth control through 30 days after the last dose of study drug.

\section{Exclusion Criteria}

1. Receiving extracorporeal membrane oxygenation (ECMO) at baseline

2. Severe organ dysfunction (SOFA score $>10$ ) at enrollment

3. Patient or LAR unable to provide written informed consent

4. ALT/AST $>3$ times the upper limit of normal or serum bilirubin $>1.5$ times the upper limit of normal

5. Estimated glomerular filtration rate (eGFR) by Modification of Diet in Renal Disease (MDRD) formula $<30 \mathrm{~mL} / \mathrm{min} / 1.73 \mathrm{~m} 2$ or on dialysis

6. Pregnancy or breast feeding.

7. Anticipated transfer to another hospital which is not a study site within 72 hours.

8. Allergy to any study medication

9. Patient not expected to survive $>24$ hours, or likely to be discharged $<24$ hours per PI discretion. 